\title{
STUDY OF CYTOIMORPHOLOGICAL FEATURES OF MYXOID SOFT TISSUE LESIONS BY FINE NEEDLE ASPIRATION CYTOLOGY
}

KEY WORDS:

\section{Arpita Joshi}

\section{INTRODUCTION}

Fine needle aspiration cytology (FNAC) was initially conceived as a means to confirm a clinical suspicion of local recurrence or metastasis of known cancer without subjecting the patient to further surgical intervention. [1]

In 1998, Akerman M highlighted the benefits of FNA when compared with core needle or open surgical biopsy. The most important were rapid preliminary diagnosis, no need for hospitalization and anaesthesia, negligible complications and fear for tumour cell spread. [2]

Soft tissue can be defined as nonepithelial extra skeletal tissue of the body exclusive of the reticuloendothelial system, glia, and supporting tissue of various parenchymal organs. [3]

Myxoid tumours of soft tissue are a heterogeneous group of tumours characterized by their abundant mucoid/myxoid extracellular matrix. [4]

Soft tissue tumors (STT) is a very wide area of interest, but cytologically, relatively less discovered. [5]

FNAC is relatively painless, produces a speedy result and is a cheap procedure and has a good sensitivity and specificity in diagnosing primary and metastatic STT. [6]

Except to categorise STT, FNAC is proved effective in differentiating benign and malignant STTs. [7]

Aim of the present study was to assess the spectrum of Soft tissue lesion with myxoid change on cytology and to estimate the sensitivity and specificity of FNAC in diagnosis of soft tissue lesions with myxoid change.

\section{MATERIAL AND METHODS}

Present study is a cross-sectional study of soft tissue lesions with myxoid change on cytology.

The data was collected from January 2017 to June 2018. The study was conducted at pathology department of a tertiary care hospital and medical College. During the study period a total of 65 cases were encountered showing myxoid change on FNAC. FNAC was done following usual protocol. The site was located. After cleaning, a 22 gauge needle attached with a $20 \mathrm{ml}$ syringe was inserted directing the tip of the needle towards the lesion. After withdrawing the needle, the aspirated material was squeezed on the clean glass slides and smears were prepared. Air dried smears were fixed in methanol for 20-30 minutes and then stained with MayGrunwald Giemsa stain. After drying, the smears were mounted with DPX and then studied under the microscope.

The cytologic findings of the smears, the clinical findings \& the radiologic findings were studied to reach to the diagnosis.

Histology was available in 17 cases out of total cases and taking histology as gold standard sensitivity, specificity, positive predictive value, negative predictive value were calculated to study the ability of FNAC in diagnosing malignancy in soft tissue lesions showing myxoid change.

\section{RESULTS}

FNA was done on 216 soft tissue swellings during the study period. Out of these, 65 (30\%) were soft tissue lesions with myxoid change. Although background myxoid change was seen in three cases, the cellularity was very scanty for cytological opinion. Hence 62 cases (95.3\%) were adequate for cytology reporting.

About 57\% (37/65) cases of soft tissue tumours with myxoid change were males and $43 \%(28 / 65)$ were females. On cytology $82.2 \%(51 / 62)$ of patients very categorised as benign while $17.8 \%(11 / 62)$ were categorised as malignant lesions. The commonest age group for benign lesions was between $2^{\text {nd }}$ to $5^{\text {th }}$ decades and malignant lesions occurred in all ages except $1^{\text {st }}$ decade of life with peak in $6^{\text {th }}$ decade. The commonest site of involvement of the benign tumours was upper limb, involved in 50\% (28/51) cases, followed by lower limb (22.5\%), head and neck (12.9\%) and abdomen. However, for malignant lesions it was the lower extremities $(22.5 \%, 7 / 11$ cases) followed by lower limb.

In our study, ganglion was found to be the most common benign myxoid soft tissue lesions (43.1\%, 22/51 cases), followed by nodular fasciitis $(19.6 \%, 10 / 51$ cases $)$, schwannoma (9.8\%) and fibromatosis (5.8\%). Dermato fibrosarcoma protuberans (DFSP) was found to be the most common malignant myxoid soft tissue lesion ( $27.2 \%, 3 / 11$ cases) followed by myxoid liposarcoma, undifferentiated pleomorphic sarcoma, which constituted $18.1 \%$ each.

The FNAC of ganglion showed low cellularity with small number of singly dispersed histiocyte like cells having abundant pale cytoplasm and a small ovoid nucleus in an abundant myxoid background.

Nodular fasciitis showed cellular aspirates. Most cells were spindle shaped, with moderate to abundant basophilic cytoplasm, well defined cell borders and bipolar cytoplasmic processes. Few plump cells with ovoid, rounded, and irregular nuclei were also found, lying against myxoid background matrix. Histology was available in only two cases confirming the cytological diagnosis.

Schwannoma showed moderate cellularity with mainly cohesive spindle cell clusters having long-slender nuclei with pointed ends and indistinct cytoplasm with at places the arrangement was suggestive of palisading. In two cases, epithelioid cells with round to oval nuclei and bland chromatin were also seen. Tumour cells were embedded in fibrillary matrix in all the cases, while myxoid matrix was noted in all the cases. Histology was available in three cases and they all of confirmed cytological opinion.

Fibromatosis cases showed low to moderate cellularity with cells arranged in clusters as well as scattered. Collagenised stroma with myxoid background was identified in three cases. Cells were spindle to oval in shape with moderate amount of basophilic cytoplasm, well defined cell borders and bipolar cytoplasmic processes. Nuclei varied from being fusiform to oval in shape with bland chromatin and inconspicuous nucleoli.

Histology was available in two cases, confirming the cytological diagnosis.

Three cases were diagnosed as spindle cell lipoma on FNAC. 
One of the cases had moderate cellularity while in the other two cellularity was poor. Smears from all the cases showed spindle cells in loose clusters as well as scattered single cells, admixed with mature adipose tissue fragments. Collagen fibres were identified in the background in one case. All cases had abundant myxoid material in the background. Mast cells were seen in both the cases. Histology was available of one case verifying the cytological diagnosis.

Three cases were diagnosed as neurofibroma on cytology. Smears revealed low cellularity with spindle cells arranged in loose clusters and few dispersed cells. Myxoid areas were seen but few fibrillary areas were also noted. Spindle cells had moderate amount of pale cytoplasm with ill-defined borders. Nuclei were elongated; some were wavy with fine granular chromatin and inconspicuous nucleoli. Histology was available in two cases and it confirmed the cytological diagnosis.

FNAC of one case of intramuscular myxoma showed moderately cellular smear with dispersed single cells and few cohesive clusters in an abundant myxoid background. Cells were elongated with ill defined, abundant basophilic cytoplasm having vacuoles with spindle to oval shaped nuclei having granular chromatin and inconspicuous nucleoli.

Three cases of DFSP were diagnosed cytologically. Smears from two aspirates were moderately cellular, while from the other was highly cellular. Cells were arranged in compact cohesive clusters and scattered single cells. Storiform pattern was observed in two cases. Cells were embedded in collagen matrix in all the smears. Myxoid background was seen in all the smears. Cells were spindled in shape with moderate to abundant, pale poorly defined cytoplasm. Nuclei were fusiform, sometimes oval, with fine granular chromatin and inconspicuous nucleoli. Histology was received for all the three cases of which two cases were DFSP while one case came out to be neurofibroma on histology.

Aspirates from two cases of myxoid liposarcoma were moderately cellular. Smears showed abundant myxoid background and fragments of branching capillary network. Cells were arranged as tissue fragments as well as dispersed. In both the cases atypical lipoblasts were seen along with small neoplastic cells. Nuclei were plump spindled shaped with fine granular chromatin and mild pleomorphism was seen. Diagnosis was confirmed on histology of one case. The other case was lost to follow-up.

Two cases were diagnosed undifferentiated pleomorphic sarcoma cytologically. Smear from one case was highly cellular while the other had scanty cellularity. Myxoid background was seen in both the cases. Cells were medium to large spindle and round to oval with varying amount of basophilic cytoplasm and marked degree of pleomorphism. Nuclei were spindle and round to oval in shape, irregular, hyperchromatic and had prominent nucleoli. No mitoses were observed in either of the cases. Histology was not available in both the cases.

Aspirate from a case which was reported as extra skeletal myxoid chondrosarcoma on cytology was moderately cellular. Smear showed clusters of uniform round to spindleshaped cells with moderate amount of wispy cytoplasm in a myxoid background. Nuclei were bland looking with finely stippled chromatin, inconspicuous nucleoli with grooving / cleaving. Histology was obtained but it came out to be epithelioid MPNST.

Aspirates from a case of malignant peripheral nerve sheath tumour were highly cellular. Smears consisted of mixture of cohesive clusters and dispersed cells. Tumour cells were embedded in a fibrillary background along with some myxoid matrix. Cells were spindle shaped with indistinct cytoplasm and elongated, wavy nuclei which had fine granular chromatin without any nucleolar prominence. Diagnosis was confirmed on histology.

One case of rhabdomyosarcoma was diagnosed cytologically. Aspirates showed moderate cellularity with predominantly single cells in a myxoid background. Cells were of spindle to oval shaped with moderate amount of basophilic cytoplasm with cytoplasmic vacuolations. Stripped nuclei were also seen in our case. Diagnosis was confirmed on histology.

Accuracy was found to be $94.1 \%$. Sensitivity and specificity of FNAC in diagnosing myxoid cell lesions of soft tissues was found to be $100 \%$ and $91 \%$ respectively. Positive and negative predictive values were $85.7 \%$ and $100 \%$ respectively.

\section{DISCUSSION}

Singh HK et al (2004) in their review article observed that in the hands of experienced cytopathologists, FNAB in conjunction with ancillary techniques has a diagnostic accuracy approaching $95 \%$ for the diagnosis of malignant soft tissue tumors. Nevertheless, it had certain limitations related to the accurate histologic grading and subtyping of certain subgroups of sarcomas. [8]

Wong NL et al (2007) conducted a FNAC data of 24 soft tissue myxoid lesions (14 benign lesions, 10 malignant lesions). The data revealed that the diagnostic accuracy of FNAC was nearly $100 \%$ in differentiating benign and malignant myxoid lesions of the soft tissues. [9]

Roy S et al (2007) concluded FNAC to be useful cost effective procedure for the diagnosis of soft tissue tumors. [10]

Basu $\mathrm{N}$ et al (2009) used cytology established the role of cytology in diagnosis of soft tissue sarcomas with good cytohistological correlation rate (87.2\%).[11]

Vijayabharathi I et al (2015) found that the diagnostic accuracy of FNAC of soft tissue tumors was $95.37 \%$, sensitivity was $84.2 \%$ and specificity $97.75 \% .[12]$

Kotwal S et al (2016) ascertained the definite role of FNAC in diagnosing soft tissue tumours, both benign and malignant, in majority of cases with no need for histopathology except in few tumours where overlapping cytological features were a big limitation. [13]

Sharath Kumar HK et al (2017) concluded that Fine needle aspiration cytology (FNAC) was a valuable tool in the diagnosis of STT combined with competent imaging and immunocytochemistry. [14]

In the present study $30 \%$ of all soft tissue tumors were found to have myxoid matrix. This was in stark contrast to the previous studies by other workers. In the study by Maitra A et al (2000) [15] and Rekhi B et al (2007) [6], myxoid lesions constituted $9.7 \%$ and $1.6 \%$ of their cases respectively. While Soni PB et al (2014)[5] reported only $4 \%$ of the cases as myxoid lesions. This disparity was due to the fact that ganglion were the commonest soft tissue swellings aspirated in our set up while Maitra A et al [15] Rekhi B et al [6] and Soni PB et al (2014) [5] have not included them in their studies. In the present study, accuracy of FNAC in diagnosing myxoid soft tissue lesions was found to be $93.8 \%$ which was comparable to other studies [15] and [16]

In the present study, males outnumbered females by a ratio of 1.3:1, which was comparable to that reported by other study (2013) [17] . Maximum number of cases in our study occurred in $2^{\text {nd }}$ to $6^{\text {th }}$ decade. Since none of the other studies focussed exclusively on myxoid soft tissue lesions, our results could not be strictly compared with them. However, in other study [17] 
and [12] , maximum number of cases were in 2 1-50 years and 21-40 years of age group respectively, which were somewhat similar to our findings. In the present study, upper limb (50\%) was found to be the most common site for myxoid soft tissue lesions, followed by lower limb (22.5\%) and head and neck (12.9\%). Rasool Z et al (2013) [18] had majority of their cases in head and neck. In the series by Vijayabharti I et al (2015) [12] and Kotwal S et al (2016) [13], lower limb was found to be the commonest site.

In the present study, $82.2 \%$ cases were found to be benign while malignant comprised only $17.8 \%$. However, our findings were in contrast to those reported by Rekhi B et al (2007) [6], in which $79.5 \%$ cases were labelled as malignant. The reason for this was the predominance of referral cases and sarcomas received by their centre.

In the present study, out of fifty one cytologically diagnosed benign myxoid soft tissue lesions, ganglion was found to be the most common tumour (43.1\%), followed by nodular fasciitis (19.6\%), schwannoma (9.8\%), fibromatosis $(5.8 \%)$ and proliferative fasciitis (1.9\%). Our findings were similar to other study [18] who reported schwannoma as the commonest benign lesion. In our study, out of eleven cytologically diagnosed malignant myxoid soft tissue lesions, dermatofibrosarcoma protuberans was found to be the most common (27.2\%), followed by myxoid liposarcoma and undifferentiated pleomorphic sarcoma, which constituted $18.1 \%$ each. other study [5],[12] reported DFSP as the commonest malignant lesion.

In the present study ten out of ten cases diagnosed as benign cytologically turned out to be benign on histology. Thus cytohistological correlation was $100 \%$ in our study. It was found to be $93 \%$ in the study by Maitra $A$ et al [15] and $90.6 \%$ by Roy et al [10]. Hence, the findings were similar. Six out of seven cytologically diagnosed malignant lesions were found to be malignant on histology while one turned out to be benign. Cytohistological correlation was $71.4 \%$. This was somewhat lower when compared to the previous studies. Maitra $A$ et al [15] found 94\% cytohistological correlation in malignant cases and Roy S et al [10] found $91.3 \%$.

Sensitivity and specificity of FNAC in diagnosing myxoid soft tissue lesions was found to be $100 \%$ and $91 \%$ respectively in our study. The figures were somewhat lower than the findings of Maitra A et al (2000) [15] and Vijayabharti I et al (2015) [12]. In the present study, PPV and NPV of FNAC were found to be $83.3 \%$ and $100 \%$ respectively. The findings were comparable to those reported by other study [12], [19] (2016).

\section{REFERENCES.}

1. Orell SR, Sterrett GF. Introduction. In: Orell SR, Sterrett GF editors. Fine Needle Aspiration Cytology.5thed.London:Elsevier;2012.p.1-7.

2. Akerman M. Fine needle aspiration cytology of soft tissue sarcoma: benefits and limitations. Sarcoma 1998;2:155-161.

3. Goldblum JR, Folpe AL, Weiss SW. Enzinger andWeiss's Soft tissue tumors. 6th ed.Philadelphia:Elsevier;2014. Chapter 1, General considerations; p.1-10.

4. Graadt van Roggen JF, Hogendoorn PCW, Fletcher CDM. Myxoid tumours of soft tissue. Histopathology 1999;35;291-312.

5. Soni PB,Verma AK, Chandoke RK, Nigam JS. A Prospective Study of Soft Tissue Tumors Histocytopathology Correlation. Pathology Research International 2014; Article ID 678628.

6. B. Rekhi, B. D. Gorad, A. C. Kakade, and R. Chinoy, "Scope of FNAC in the diagnosis of soft tissue tumors-a study from a tertiary cancer referral center in India," CytoJournal, vol. 4, article 20,2007.

7. P. Dey, M. K. Mallik, S. K. Gupta, and R. K. Vasishta, "Role of fine needle aspiration cytology in the diagnosis of soft tissue tumours and tumour-like lesions," Cytopathology, vol. 15,no. 1,pp.32-37,2004.

8. Singh HK, Kilpatrick SE, Silverman JF. Fine needle aspiration biopsy of soft tissue sarcomas: utility and diagnostic challenges. Adv Anat Pathol 2004;11:24-37.

9. Bing Z. Fine needle aspiration cytology of myxoid lesions of soft tissues: a study of 24 cases. CJP. 2007;36(9):619-23.

10. Roy S, Manna AK, Pathak S, Guha D. Evaluation of Fine Needle Aspiration Cytology and its correlation with Histopathological Findings in Soft Tissue Tumors. J of Cytol 2007;24:37-40.

11. Basu N, Biswas P, Mallick MG, Mondal SK, Sengupta S. Role of cytology in diagnosis of soft tissue sarcomas with special reference to false positive cases. Journal of Cytology 2009;26:15-19.

12. I Vijayabharathi, A. Bhagyalakshmi Atla, U. Ramesh,L.Praveen Kumar, R.
Manasa. Cytohistopathological Correlation of Soft Tissue Tumors: A Retrospective Study. J of Evidence Based Med and Hlthcare 2015;2:40224033.

13. Kotwal S, Gupta D, Suri J. Role of fine needle aspiration cytology in diagnosis of soft tissue tumors; benefits and limitations: a two year retrospective study.J evid based med healthcare 2016;3: 1019-1024.

14. Sharath Kumar HK, Gayathri MN, Shailaja MD. Cytopathology of soft tissue tumors with their varying presentations. JMSCR 2017;5:15350-15354.

15. Maitra A, Ashfaq R, Saboorian MH, Lindberg G, Gokaslan ST. The role of fine needle aspiration biopsy in the primary diagnosis of mesenchymal lesions. Cancer Cytopathology 2000; 90: 178-185

16. Parajuli S, Lakhey M.Efficacy of fine needle aspiration cytology in diagnosing soft tissue tumors.Journal of Pathol of Nepal 2012;2:305-08.

17. Tailor HJ, Bhagat VM, Kaptan KBR, Italiya SL, Balar HR, Agarwal MP. Diagnostic accuracy of fine needle aspiration cytology in soft tissue tumors: our institutional experience. Int J Res Med Sci 2013;1:443-447.

18. Rasool Z, Bhat ML, Samoon N, Baba K, Rumana M, Reshi R. Utility of FineNeedle Aspiration Cytology in Diagnosis of Soft Tissue Lesions with Histopathological Correlation. GJMEDPH 2013;2:1-7

19. Arul P, Masilamani S. Fine needle aspiration cytology of soft tissue tumors with its histopathological correlation in a rural hospital of South India: A retrospective study. Clin Cancer Investig J 2016;5:146-50 